\title{
Torsional Vibration Attenuation Characteristics and Stiffness Identification of Flexible Coupling in Vehicle Power Train
}

\author{
Shengping Fu $\mathbb{D}^{1},{ }^{1}$ Ning Luo ${ }^{(D)},{ }^{2,3}$ Hanlin Huang, ${ }^{3}$ Yuhang Zhou, ${ }^{3}$ and Wei Ming ${ }^{3}$ \\ ${ }^{1}$ School of Mechanical and Energy Engineering, Jimei University, Xiamen, Fujian, China \\ ${ }^{2}$ Engineering Science, Chung Hua University, Hsinchu, Taiwan \\ ${ }^{3}$ School of Mechanical and Automotive Engineering, Xiamen University of Technology, Xiamen, Fujian, China \\ Correspondence should be addressed to Shengping Fu; 7025370@163.com and Ning Luo; nluo@xmut.edu.cn
}

Received 30 May 2020; Revised 10 September 2020; Accepted 26 October 2020; Published 12 November 2020

Academic Editor: Peter Múčka

Copyright (c) 2020 Shengping Fu et al. This is an open access article distributed under the Creative Commons Attribution License, which permits unrestricted use, distribution, and reproduction in any medium, provided the original work is properly cited.

Flexible coupling is one of the crucial components for vibration attenuation used in vehicle power train. Vibration attenuation characteristics and stiffness identification of flexible coupling are profoundly studied aiming at one vehicle power train. Firstly, the dynamics model of each crucial transmission component in power train is constructed. And the torsional vibration model of power train is established according to the concentrated mass method. The effects of coupling stiffness on vibration responses of power train are thoroughly analyzed based on system concentrated mass dynamics model. Secondly, the sensitivities of natural frequency and main forced vibration response parameters are calculated. The coupling stiffness is proved to be a sensitive parameter. Finally, taking the Geislinger coupling as an example, the damping and stiffness characteristics are acquired according to the parameter identification method based on the quantity of test data. The results provide the theory basis for the dynamics optimization of power train.

\section{Introduction}

The power train is one of the vehicle crucial systems, which consists of an engine, a flexible coupling, a gearbox, et al. Torsional vibration is a general phenomenon for vehicle powertrain, which directly affects vehicle driving comfort and safety. The torsional dynamics characteristics of vehicle powertrain are complicated because of the multidegree of freedom and different kinds of excitation. And vehicle powertrain with different parameters (inertia, stiffness, damping, etc.) has different torsional vibration behaviors. When the excitation frequency is close to the system natural frequency, resonance vibration occurs, which will reduce the reliability, durability, and comfort of the vehicle. Therefore, it is necessary to explore the system natural characteristics, the additional torsional working stress of the transmission parts, and the method of attenuating torsional vibration. The flexible coupling bridges two rotating components, not only compensating the relative displacement, but also behaving the function of cushioning and absorbing vibration. It is widely used in vehicle power train to change the torsional dynamics behaviors. So, it is important to identify coupling dynamics parameters for system dynamic optimization. The research on torsional vibration of vehicle power train mainly focuses on the following aspects.

(1) Torsional vibration modeling and analysis: the torsional vibration model of power train is simplified as one multi-degree-of-freedom analysis model with concentrated mass-stiffness-damping parameters in the previous researches, which has been verified by large quantity of calculation and test data [1-5]. And sensitivities characteristics of main free and forced vibration parameters are important. Derivation method, mode iterative method, expanding rank method, nonlinear mode synthesis method, and other methods have been proposed for sensitivity analysis to supply theory references of system dynamics optimization [6-9]. (2) Torsional vibration control: the vibration attenuation performances of torsion damper, active vibration 
absorption, flexible coupling, etc., are explored to seek for the reasonable and effective method of vibration attenuation [10-13].

A dual mass flywheel is extensively used for the torsional vibration attenuation of vehicle power train. Viktor Berbyuk studied the feasibility of the application of a dual mass flywheel (DMF) for heavy-duty truck drivetrain system [14]. And the optimized mass inertia, stiffness, and damping parameters of a DMF were proved to provide the better attenuation of the torque oscillations. Zeng Liping et al. established the torsional vibration model of the vehicle powertrain system equipped with the DMF and the corresponding nonlinear differential equations considering the friction torque and the piecewise stiffness owing to the clearance of the damping spring in the DMF [15]. Paul D. Walker numerically investigated the influence of nonlinearities applied to vehicle powertrains equipped with a dual clutch transmission, including gear backlash, dual mass flywheel hysteresis, and torque pulses from the engine [16]. Zhao Chen analyzed the action mechanism and parameter matching characteristics of dual mass flywheel. The experimental results show that the matched dual mass flywheel had a good effect on reducing vibration and noise [17].

The flexible coupling is one of the crucial vehicle components for system resonance frequency shift and vibration attenuation. The damping performances of flexible coupling for power train system were widely studied $[12,18,19]$. The stiffness and damping parameters of flexible coupling were identified by numerical simulation and test $[20,21]$. And the traits of some special types were also investigated. Yuanfeng Xia analyzed the deformation of a hexangular flexible coupling connecting two rigid rotors which have angular and parallel misalignment and calculated the dynamic reaction force varying with rotational angle [22]. Kang-Hyun Lee proposed the design of an magnetorheological elastomer flexible coupling whose torsional stiffness can be controlled by an embedded magnetic field generator [23].

The stiffness of the Geislinger coupling changes with the variation of the transmission angle. It is coupled with system dynamics characteristics. Therefore, the parameter identification of flexible coupling is important for the dynamics analysis of vehicle power train. According to the dynamics characteristics and sensitivity analysis of some vehicle power train, one method of stiffness and damping identification of flexible coupling based on the frequency response data of bench test is presented.

\section{Studied Vehicle Power Train}

The double-flow hydraulic-mechanic powertrain of a tracked vehicle is investigated. It consists of a $V$ type 12 engine, a coupling, a front transmission, a torque converter, a gearbox, et al. Figure 1 shows the simplified model of the power train. The introduction of gear shifting method with corresponding wet clutch is shown in Table 1. "O" indicates a combination of wet clutch. It is known from Table 1 that the 1st, 2nd, and 3rd gears work under the hydraulic condition.
Though, the 4th, 5th, and 6th gears work under the mechanical condition with a certain gear ratio.

The required working life of the transmission system is 800 hours. And the assigned working time of each shift gear is shown in Table 2 . The 4 th, 5 th, and 6 th gears are used more frequently. Therefore, these three gears are selected to be studied.

\section{Stiffness Characteristics of Flexible Coupling}

A Geislinger coupling with internal oil injection, as shown in Figure 2, is simplified as a dual-inertia torsional dynamics model for the study of frequency shift and vibration attenuation in the powertrain.

The torsional stiffness $k_{c}$ and damping $c_{c}$ of the Geislinger coupling change with excitation frequency $\omega$ [24].

$$
\begin{aligned}
& k_{c}= \begin{cases}k_{\mathrm{cs}}\left(1+0.37 \frac{\omega}{\omega_{c 0}}\right), & 0 \leq \omega \leq \omega_{c 0}, \\
k_{\mathrm{cs}}\left(1.1+0.27 \frac{\omega}{\omega_{c 0}}\right), & \omega \geq \omega_{c 0},\end{cases} \\
& c_{c}=\frac{\kappa k_{c}}{\omega_{G}},
\end{aligned}
$$

where $\omega_{G}$ is the angular frequency of external excitation, $\omega_{c 0}$ is the natural frequency of coupling, $k_{\mathrm{cs}}$ is the static stiffness of coupling, and $\kappa$ is the damping factor.

The vibration responses vary with the angular frequency of external excitation. It shows that the coupling stiffness is also associated with the torsional vibration responses. Therefore, it is feasible to identify the coupling stiffness from the torsional vibration response of the system.

The damping depends on the working state of the internal oil-filled Geislinger coupling [24]. And the fluid damping is neglected. $\kappa$ is expressed as follows:

$$
\kappa=0.02+0.0191 \frac{T_{0}}{T_{\mathrm{KN}}}+0.1619\left(\frac{T_{0}}{T_{\mathrm{KN}}}\right)^{2},
$$

where $T_{0}$ is the stable working torque of coupling and $T_{\mathrm{KN}}$ is the rated coupling torque.

\section{Torsional Vibration Analysis}

According to the concentrated mass method, the power train is theoretically regarded as a system consisting of rigid bodies and flexible shafts. And it is simplified as a concentrated inertia and stiffness system with multidegree of freedom. In addition, the following modeling assumptions are proposed: (1) the concentrated mass point of each component with relatively large inertia is in the centerline of the rotating surface of each component; (2) the inertia of transmission shaft bridging two concentrated mass points is evenly distributed to these two mass points; (3) the system clearance is neglected, and the power train is simplified as a linear multi-degree-offreedom system composed of inertia and flexible 


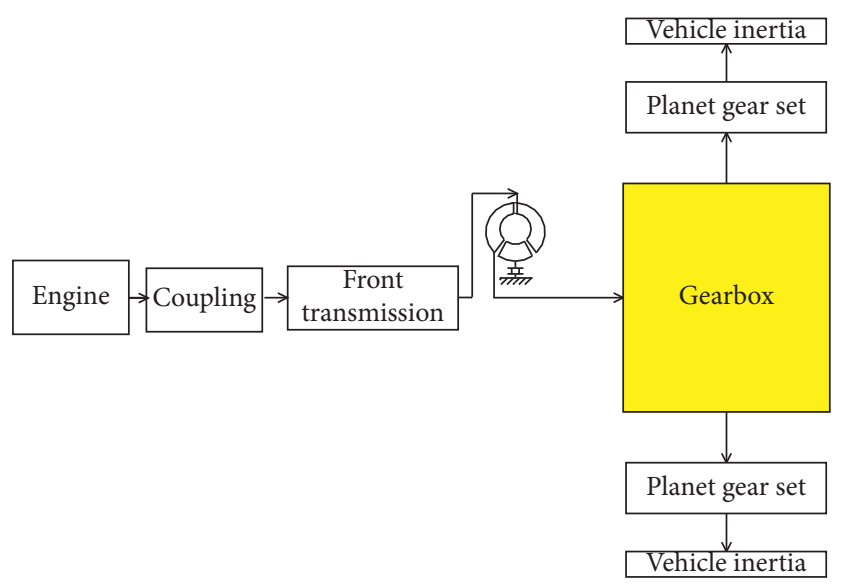

(a)

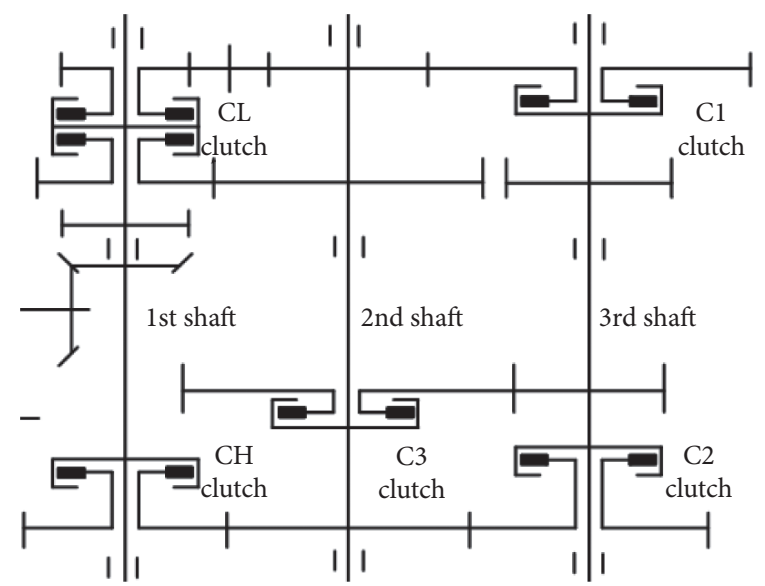

(b)

FIGURE 1: Schematic diagram of the studied vehicle power train. (a) Arrangement diagram. (b) Transmission diagram of gearbox.

TABLE 1: The list of each gear operation method.

\begin{tabular}{lccccccc}
\hline & 1 & 2 & 3 & 4 & 5 & 6 & Reverse \\
\hline $\mathrm{CH}$ & $\bullet$ & $\bullet$ & $\bullet$ & $\bullet$ & $\bullet$ & $\bullet$ \\
$\mathrm{C}$ CR & $\bullet$ & $\bullet$ & & & & \\
$\mathrm{C} 1$ & $\bullet$ & & $\bullet$ & $\bullet$ & & & $\bullet$ \\
$\mathrm{C} 2$ & & & & & $\bullet$ \\
$\mathrm{C} 3$ & & & & & $\bullet$ \\
Transmission ratio & Continuous & Continuous & Continuous & 3.41 & 2.37 & 1.62 & $\cdots$ \\
\hline
\end{tabular}

TABLE 2: The working life of each gear.

\begin{tabular}{lcccccc}
\hline 1st (\%) & 2nd (\%) & 3rd (\%) & 4th (\%) & 5th (\%) & 6th (\%) & Reverse (\%) \\
\hline 2 & 5 & 15 & 25 & 30 & 18 & 5 \\
16 & 40 & 120 & 200 & 240 & 144 & 40 \\
\hline
\end{tabular}

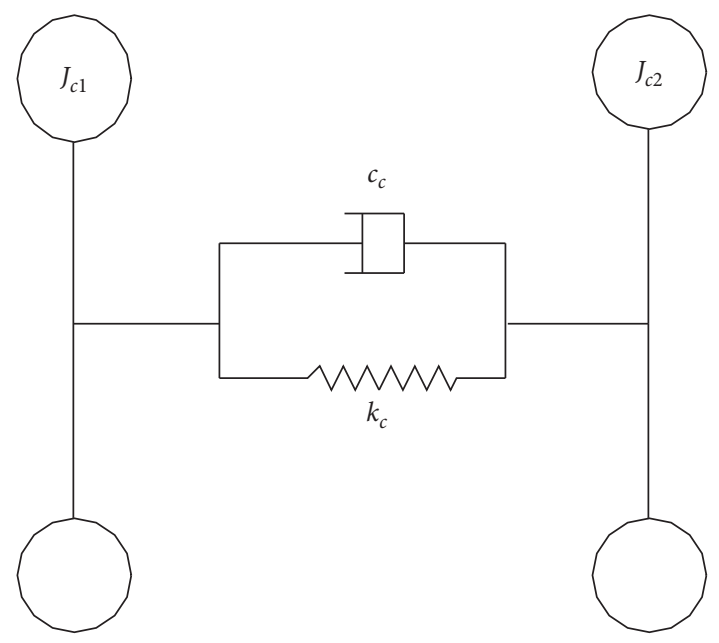

FIGURE 2: Dynamics model of Geislinger coupling.

elements; (4) the wet clutch driving part is rigidly connected to the driven part when the wet clutch is fully engaged.

\subsection{Excitation}

4.1.1. Gear Pair. The simplified torsional vibration model of a gear pair is shown in Figure 3. $k_{g}$ is the meshing stiffness. $c_{g}$ is the meshing damping. $e_{\mathrm{g}}$ is the comprehensive error of a gear pair.

According to Ishikawa's formula (references), the mesh stiffness of the involute pair is calculated. Figure 4 shows the mesh stiffness of gear pair (26/33) with the input speed $1000 \mathrm{r} / \mathrm{min}$ and the torque $900 \mathrm{~N} . \mathrm{m}$.

Moreover, $c_{\mathrm{g}}$ and $e_{\mathrm{g}}$ are interpreted as follows:

$$
\begin{gathered}
c_{g}=2 \xi_{g} \sqrt{\frac{k_{g} R_{g 1} R_{g 2} J_{g 1} J_{g 2}}{R_{g 1}^{2} J_{g 1}+R_{g 2}^{2} J_{g 2}},} \\
e_{g}(t)=e_{0}+e_{r} \sin \left(\frac{2 \pi t}{T_{g}+\phi_{g}}\right),
\end{gathered}
$$

where $R_{g 1}$ and $R_{g 2}$ are the radius of driving and driven gear, respectively; $J_{g 1}$ and $J_{g_{2}}$ are the inertias of driving and driven gear, respectively; $\xi_{\mathrm{g}}$ is the meshing damping ratio, $\xi_{g}=0.03 \sim 0.17 ; e_{0}$ and $e_{r}$ are the constant and amplitude of gear teeth error, respectively; $e_{0}=0$, $e_{r}=f_{\mathrm{pb} 1}+f_{\mathrm{pb} 2}+0.5\left(f_{f 1}+f_{f 2}\right) ; f_{f 1}$ and $f_{f 2}$ are the profile tolerance of driving and driven gear; $f_{\mathrm{pb} 1}$ and $f_{\mathrm{pb} 2}$ are the base pitch deviation of driving and driven gear; $T_{g}$ is the meshing period; and $\phi_{g}$ is the phase angle, $\phi_{g}=0$. 


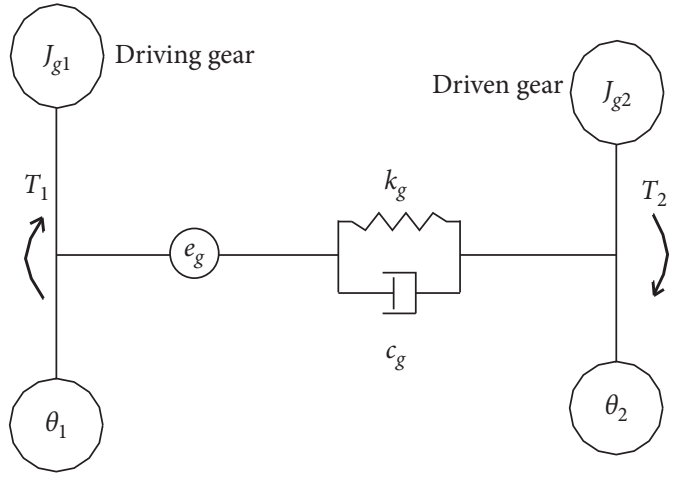

FIgURE 3: The dynamics model of a gear pair.

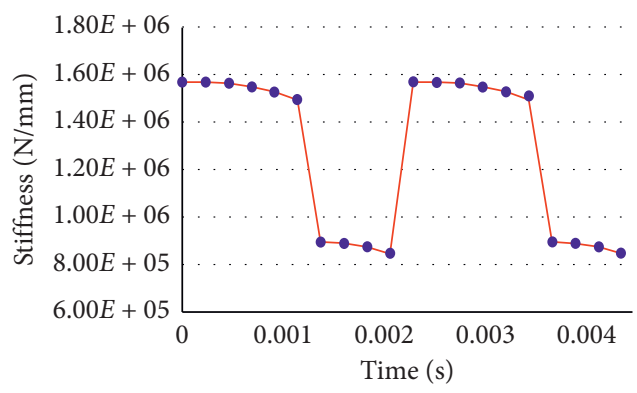

Figure 4: The meshing stiffness of the gear pair.

The transmission shaft is simplified as a torsional flexible system without the consideration of its inertia. And its equivalent torsional stiffness and damping are shown as follows:

$$
\begin{aligned}
& k_{s}=G_{s} I_{\mathrm{ps}}, \\
& c_{s}=\frac{0.02}{\pi \omega_{s}} k_{s},
\end{aligned}
$$

where $G_{s}$ is the shaft shear modulus, $I_{\mathrm{ps}}$ is the polar moment of inertia of the cross section, and $\omega_{s}$ is the shaft natural frequency.

4.1.2. Engine Periodic Excitation. When the engine works at a constant speed, the engine output torque will pulsate periodically. The pulsation originates from the combustion pressure, inertial force, and the gravity of the reciprocating parts, which causes torsional vibration of the power train. Based on the concentrated mass method, the output torque of the single cylinder of the studied engine is obtained as shown in Figure 5.

According to harmonic analysis and Fourier transform, the engine output torque working at $2000 \mathrm{r} / \mathrm{min}$ is obtained, as shown in Figure 6.

4.1.3. Hydraulic Torque Convertor. A 3-element centripetalturbine hydraulic torque convertor is adopted in the studied power train. The stator inertia is neglected compared with the turbine and pump wheel. And the simplified dynamics model is shown in Figure 7.

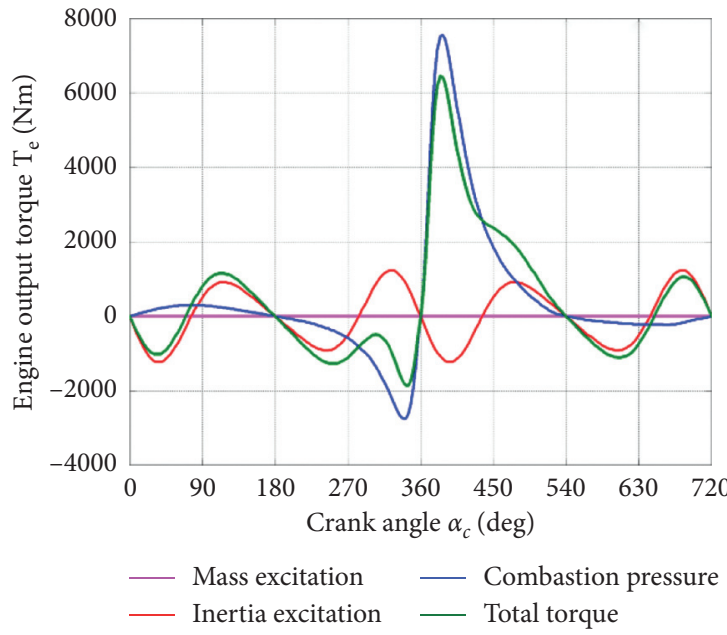

FIgURE 5: The torsional torque of the single cylinder.

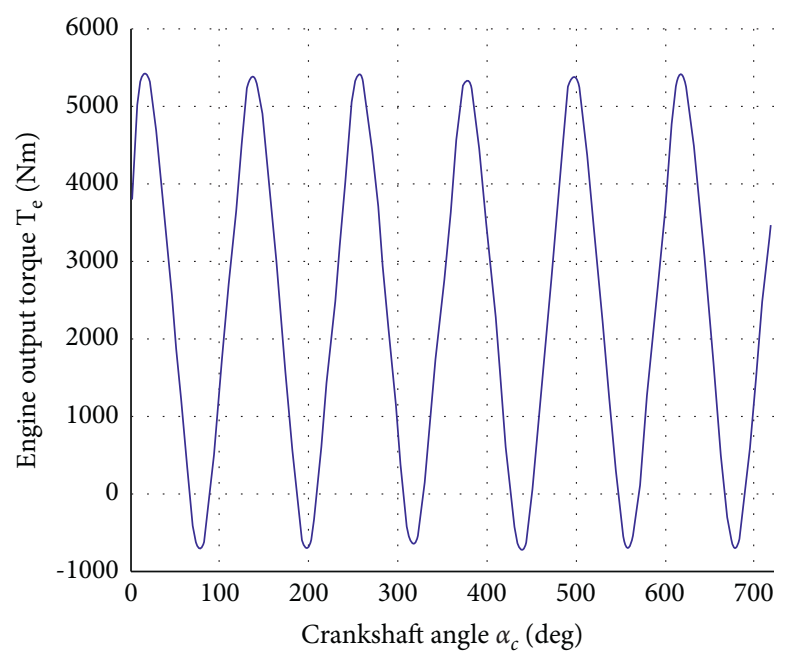

Figure 6: The engine output torque.

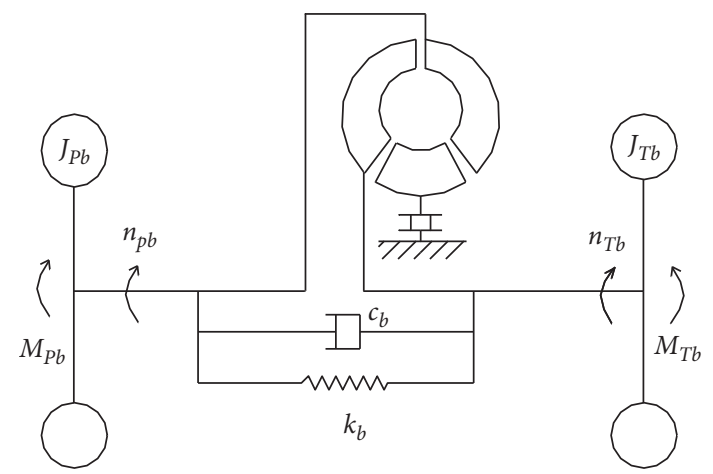

Figure 7: Dynamics model of the hydraulic torque convertor.

$M_{\mathrm{Pb}}$ and $M_{\mathrm{Tb}}$ are the torque of the pump wheel and the turbine wheel. $n_{\mathrm{Pb}}$ and $n_{\mathrm{Tb}}$ are the torsional speed of the pump wheel and the turbine wheel. $J_{\mathrm{Pb}}$ and $J_{\mathrm{Tb}}$ are the equivalent inertia of the pump wheel and the turbine wheel. 
$k_{b}$ is the torsional stiffness of power transmission between the pump wheel and the turbine wheel. $c_{b}$ is the viscous damping coefficient of the hydraulic torque convertor. Since the power is transmitted by the variation of transmission oil kinetic energy in hydraulic torque convertor, the hydraulic torque convertor is equivalent to a power transmission system with large damping force and low rigidity. Therefore, $k_{b}$ is set to be 0 .

According to [24], the viscous damping coefficient of the hydraulic torque convertor $c_{b}$ is

$$
c_{b}=\frac{2\left(M_{P b}-M_{T b} i_{b}\right)}{\sum_{r} \omega_{r} D_{r}^{2}},
$$

where $D_{r}=\sqrt{A_{r}^{2}+B_{r}^{2}}$ and $i_{b}$ is the transmission ratio of the hydraulic torque convertor.

4.2. System Torsional Dynamics Model. Based on the aforementioned assumptions and excitations calculation, the torsional dynamics model of the studied vehicle powertrain (shown in Figure 1) at the 6th gear is constructed in Figure 8.

The forced torsional vibration function of the power train is shown as follows:

$$
\mathbf{J} \ddot{\varphi}(t)+\mathbf{C} \dot{\varphi}(t)+\mathbf{K} \varphi(t)=T_{e},
$$

where $\mathbf{J}, \mathbf{C}$, and $\mathbf{K}$ are system inertia, damping, and stiffness matrix, respectively; $\varphi(t), \dot{\varphi}(t)$, and $\ddot{\varphi}(t)$ are column vectors of torsional angle displacement, speed, and acceleration; and $T_{e}$ is the fluctuate engine torque.

The system matrix method is adopted to solve the multidegree-of-freedom torsional vibration equations. Both the system natural mode parameters and the forced vibration responses are solved.

4.3. The Effects of Coupling Stiffness. The coupling stiffness is coupled with the dynamics behaviors of the vehicle powertrain. It is essential to explore the effects of coupling stiffness on system mode parameters and forced vibration responses. The engine rated speed is set to $2200 \mathrm{r} / \mathrm{min}$. Figure 9 shows the variation curve of the natural frequency of the power train from the 1st order to the 4th order associated with different coupling stiffness at the 4 th, 5 th, and 6 th gear shift.

Figure 9 indicates that it is an effective method for the frequency shift of vehicle power train by changing the coupling stiffness. The range of engine working speed is so wide that it is impossible to make all critical speeds of different order shift beyond the range of resonance speed, especially for system natural frequency higher than the 3rd order. Therefore, it is necessary to calculate the forced vibration responses with different coupling stiffness to quantify the vibration attenuation.

According to the calculation results of the forced vibration equation, the influence of the coupling stiffness on the maximum additional torsional stress of the transmission system within the working speed range of the engine is analyzed, as shown in Figure 10. And the additional torsional angles of some special mass points are also calculated and shown in Figure 11.

Figure 10 shows that there is a peak stress of gear transmission shaft within the reasonable range of coupling stiffness. And the working stress decreases as the coupling stiffness increases in the special stiffness region. Moreover, it indicates that the method of adjusting coupling stiffness is effective for vibration attenuation.

Figure 11 shows that the three curves are consistent with each other. And the additional torsional angle of the coupling driven part is lower than that of the coupling driving part (engine flying wheel). The peak values of all three curves appear when the coupling stiffness is around $2.5 \mathrm{MNm} / \mathrm{rad}$. Furthermore, the additional torsional angle reduces significantly as the coupling stiffness increases from about $2.5 \mathrm{MNm} / \mathrm{rad}$ to $5 \mathrm{MNm} / \mathrm{rad}$. It shows that it is feasible to adjust torsional vibration amplitude by selecting the appropriate coupling stiffness.

\section{Sensitivity Analysis}

The vibration sensitivity analysis is used to quantify the effects of discrete mass, stiffness, and damping on the natural frequencies and vibration modes of the system.

5.1. Natural Frequency Sensitivity. It is assumed that the system inertia matrix $\mathbf{J}$ is a positive definite matrix. The natural frequency $\omega_{i}$ and mode vector $\varphi_{i}$ conform to the following formula:

$$
\left\{\begin{array}{l}
\left(\mathbf{K}-\omega_{i}^{2} \mathbf{J}\right) \varphi_{i}=0, \\
\varphi_{i}^{T} \mathbf{J} \varphi_{i}=A_{i} .
\end{array}\right.
$$

The sensitivity formulas of natural frequency to system inertia and stiffness are derived as follows: 

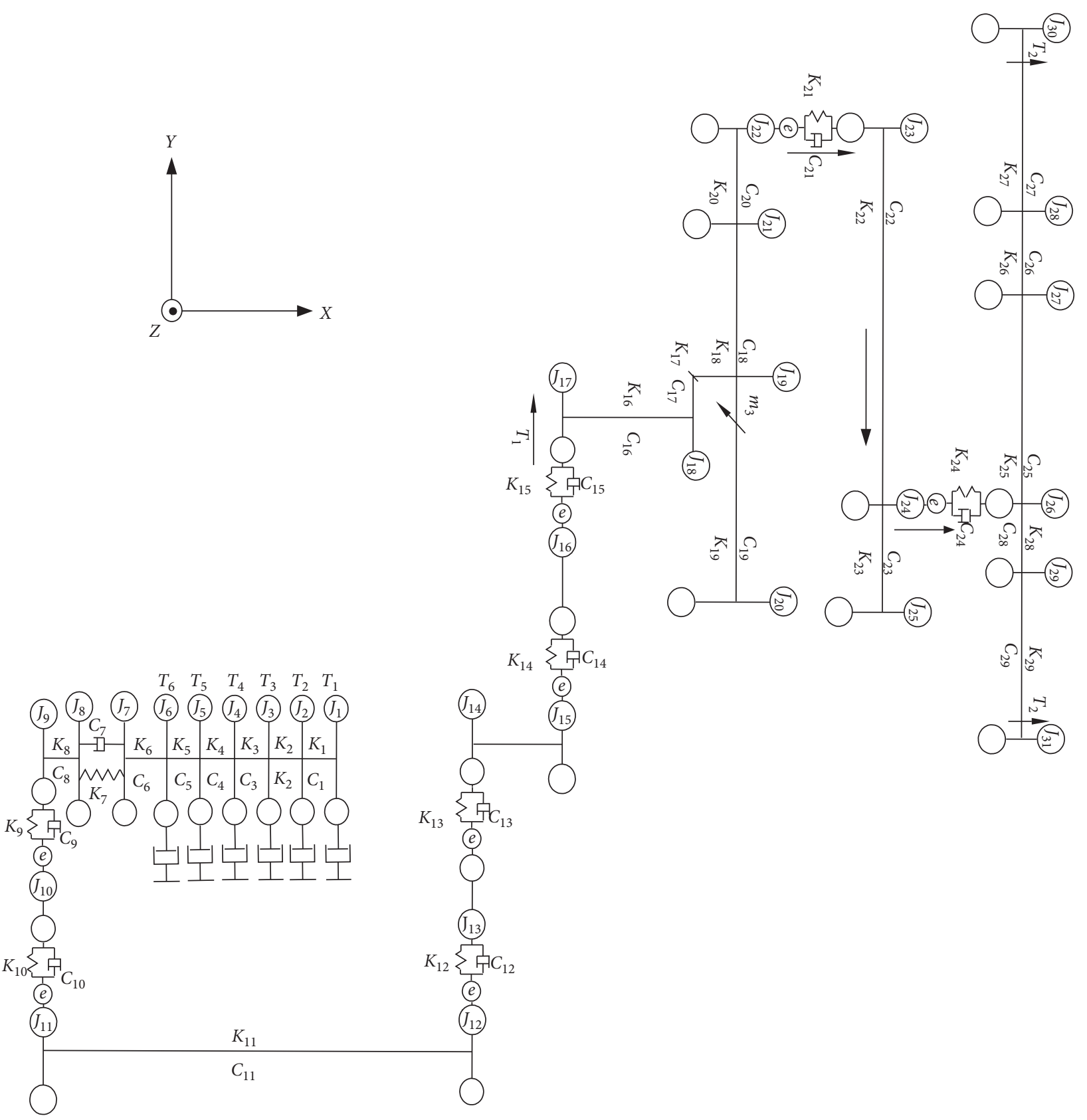

FIgURE 8: System torsional vibration dynamics model of the 6th gear.

$$
\left\{\begin{array}{l}
\frac{\partial \omega_{i}}{\partial J_{j}}=-\frac{\omega_{i}^{2} \varphi_{i}^{T}\left(\partial J / \partial J_{j}\right) \varphi_{i}}{2 \omega_{i} A_{i}}=-\frac{\omega_{i}\left(\varphi_{i}\right)_{j}^{2}}{2 \varphi_{i}^{T} \mathbf{J} \varphi_{i}}=-\frac{\omega_{i}\left(\widehat{\varphi}_{i}\right)_{j}^{2}}{2}, \\
\frac{\partial \omega_{i}}{\partial K_{j}}=\frac{\varphi_{i}^{T}\left(\partial K / \partial K_{j}\right) \varphi_{i}}{2 \omega_{i} A_{i}}=\frac{\left[\left(\varphi_{i}\right)_{j}-\left(\varphi_{i}\right)_{j+1}\right]^{2}}{2 \omega_{i} \varphi_{i}^{T} \mathbf{J} \varphi_{i}}=\frac{\left[\left(\widehat{\varphi}_{i}\right)_{j}-\left(\widehat{\varphi}_{i}\right)_{j+1}\right]^{2}}{2 \omega_{i}}
\end{array}\right.
$$

where $\widehat{\varphi}_{i}=\left(\varphi_{i} / \sqrt{A_{i}}\right)$. 

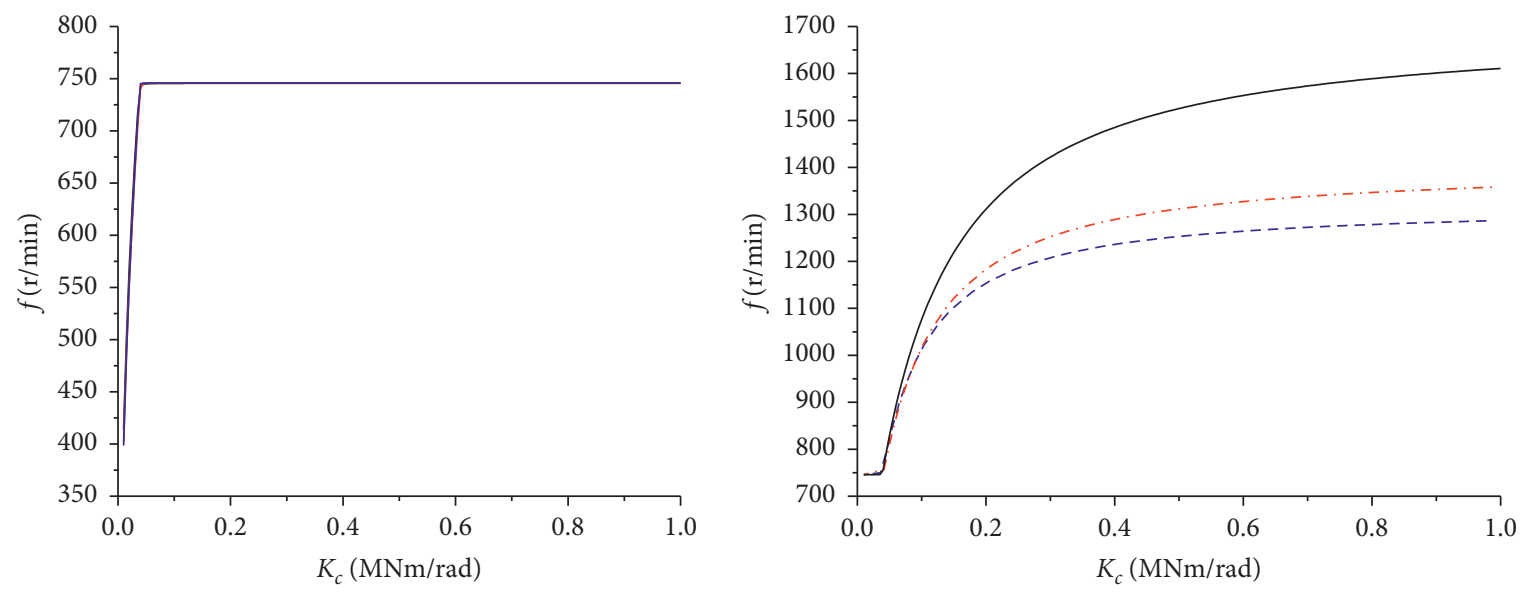

The 6th gear shift

— The 4th gear shift

(a)

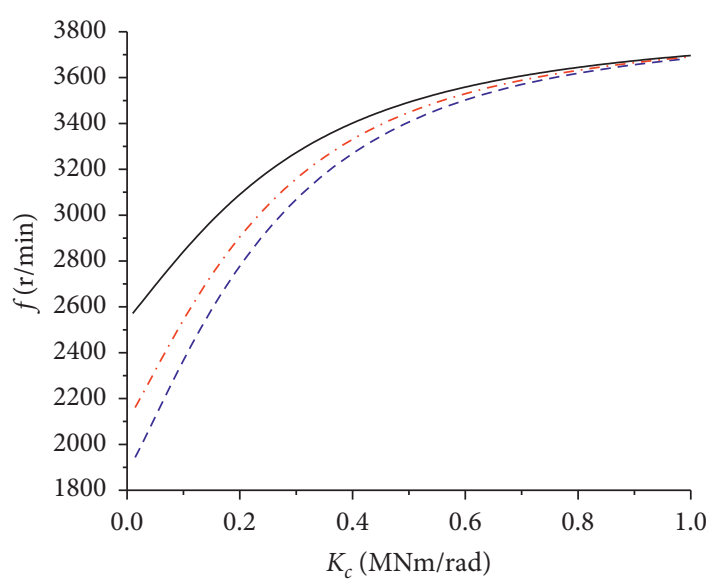

$-\ldots$ The 4 th gear shift
.-- The 5 th gear shift
_ The 6 th gear shift

(b)

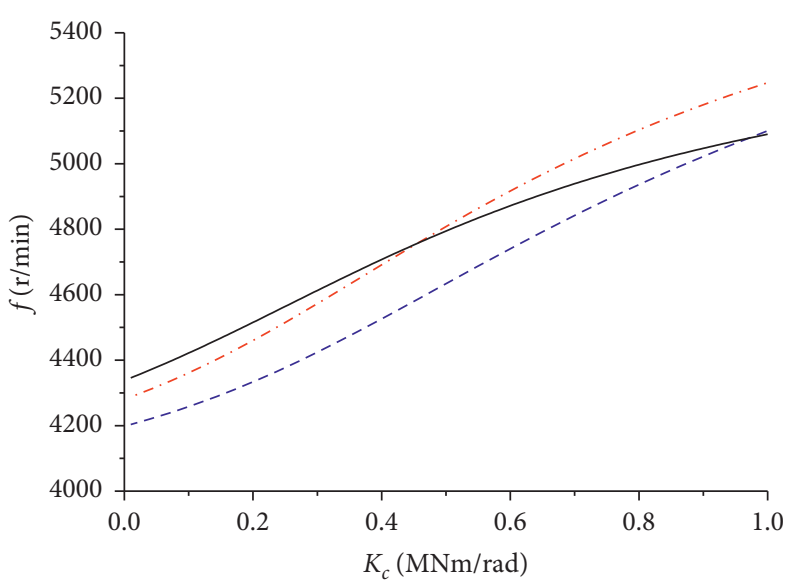

- - - The 4th gear shift

- - - The 4th gear shift

-.. The 5 th gear shift

- The 6th gear shift

(d)

Figure 9: The effect of coupling stiffness on system natural frequency. (a) The 1st-order natural frequency. (b) The 2nd-order natural frequency. (c) The 3rd-order natural frequency. (d) The 4th-order natural frequency.

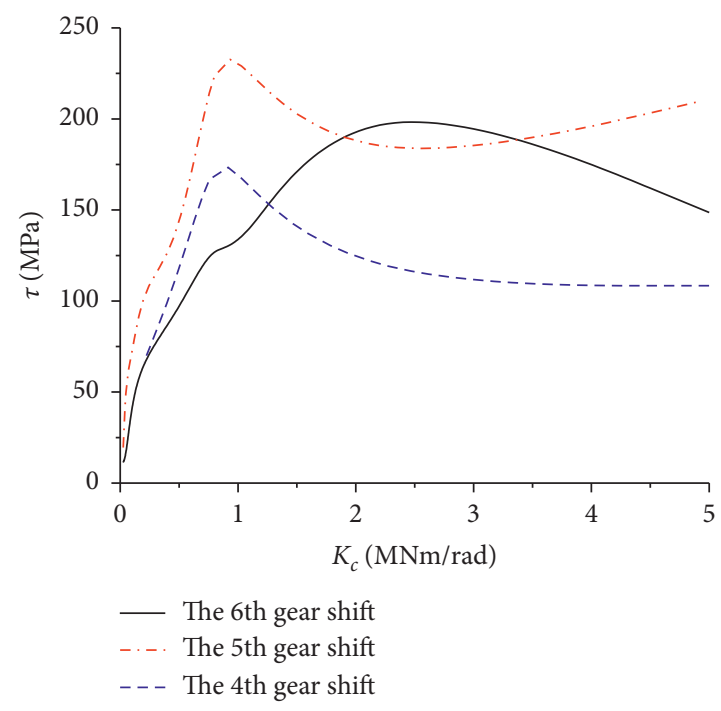

Figure 10: The max working stress of transmission shaft. 


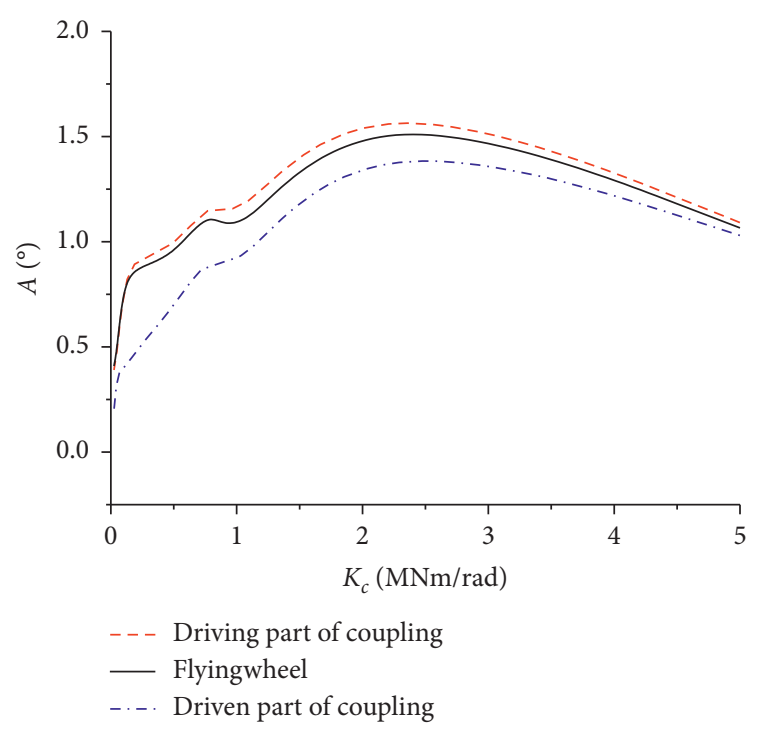

FIgURE 11: The additional torsional angle.

Therefore, the sensitivity of the natural frequency to the inertia of a certain mass point is in proportion to the square of the angle displacement of the mass point. And the sensitivity of natural frequency to certain shaft stiffness is proportional to the square of the difference value, which is the relative angular displacements of the two mass points on one shaft. The most sensitive inertia is the mass inertia with the largest angular displacement. And the most sensitive stiffness is the shaft stiffness which bridges two mass points with the maximum relative difference of two angular displacements.

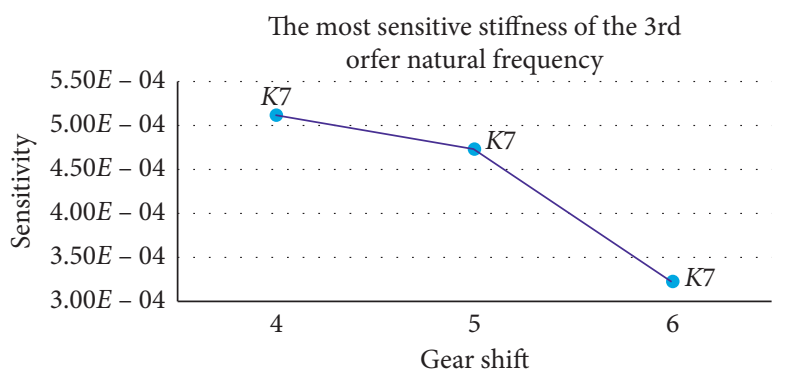

FIgURE 12: The sensitivities of natural frequency to $K_{7}$ at the $3 \mathrm{rd}$ shift.

According to formula (9), the sensitivities of natural frequency to the system inertia and the stiffness are calculated. Both $J_{22}$ and $J_{23}$ are the most sensitive inertia aiming at different gear shifts, while $K_{7}, K_{18}$, and $K_{19}$ are the most sensitive stiffness also aiming at different gear shifts. $J_{22}$ and $J_{23}$ are the gear inertias. $K_{7}$ is the coupling stiffness. $K_{18}$ and $K_{19}$ are the transmission shaft stiffness. Figure 12 shows the sensitivities of natural frequency to $K_{7}$ at the 3 rd order.

5.2. Vibration Mode Sensitivity. Based on formula (8), the sensitivity formulas of vibration mode to system inertia and stiffness are derived as follows:

$$
\left\{\frac{\partial \varphi_{i}}{\partial J_{j}}=\sum_{v=1}^{n} \alpha_{v} \varphi_{v}, \frac{\partial \varphi_{i}}{\partial K_{j}}=\sum_{v=1}^{n} \beta_{v} \varphi_{v}\right.
$$

where $\alpha_{v}$ and $\beta_{v}$ are interpreted as follows:

$$
\begin{aligned}
& \alpha_{v}= \begin{cases}\frac{\omega_{i}^{2}}{\left(\omega_{i}^{2}-\omega_{v}^{2}\right) A_{v}}\left(\varphi_{v}\right)_{j} \cdot\left(\varphi_{v}\right)_{j}, & (v \neq i), \\
-\frac{\left(\varphi_{i}\right)_{j}^{2}}{2 A_{i}}, & (v=i),\end{cases} \\
& \beta_{v}= \begin{cases}\frac{\omega_{i}^{2}\left[\left(\varphi_{v}\right)_{j} \cdot\left(\varphi_{i}\right)_{j}+\left(\varphi_{v}\right)_{j+1} \cdot\left(\varphi_{i}\right)_{j+1}-\left(\varphi_{i}\right)_{j} \cdot\left(\varphi_{v}\right)_{j+1}-\left(\varphi_{v}\right)_{j} \cdot\left(\varphi_{i}\right)_{j+1}\right]}{\left(\omega_{v}^{2}-\omega_{i}^{2}\right) A_{v}}, & (v \neq i), \\
0, & (v=i) .\end{cases}
\end{aligned}
$$

The nodes of the 3rd- and 4th-order vibration mode are located between the 5th and 6th mass point. Therefore, the most sensitive parameters of relative vibration amplitude and sensitivity are obtained for the 5th and 6th mass point. $J_{4}, J_{6}$, and $J_{7}$ are the most sensitive inertia aiming at different gear shifts. And $K_{7}, K_{16}$, and $K_{27}$ are the most sensitive stiffness aiming at different gear shifts. $J_{4}$ is the equivalent inertia of the 4 th crank-link system. $J_{6}$ is the equivalent inertia of the 6th crank-link system. $J_{7}$ is the driving part of coupling. $K_{16}$ and $K_{27}$ are the stiffness of transmission shaft. 


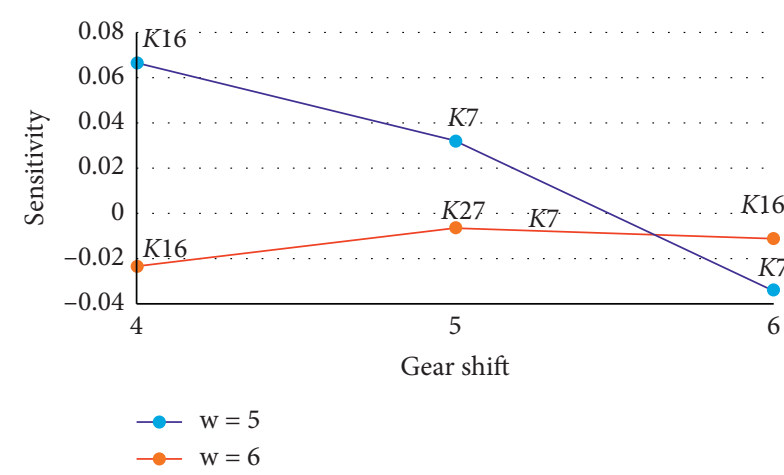

(a)

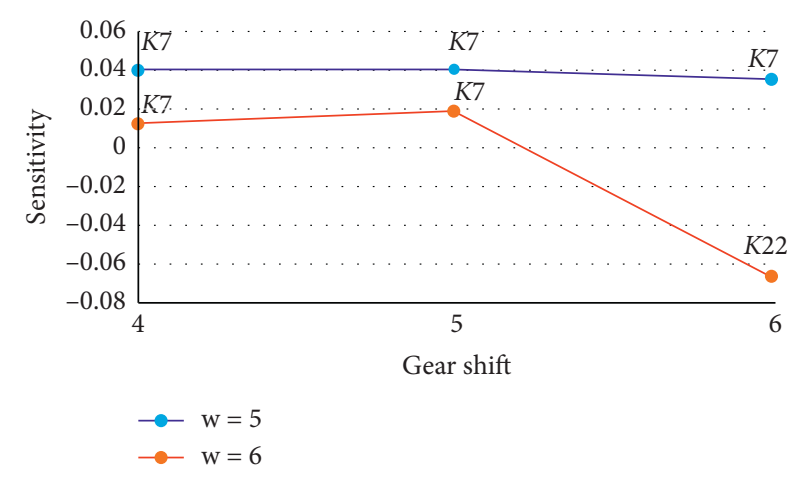

(b)

Figure 13: The most sensitive parameters of vibration mode under the 3rd and 4th order from the 3rd to 4th gear. (a) The most sensitive stiffness of the 3rd-order vibration mode. (b) The most sensitive stiffness of the 4th-order vibration mode.

Figure 13 shows the most sensitive stiffness of the 3 rd- and 4 th-order vibration modes from gear 3 to gear 4 .

5.3. Forced Vibration. The vibration working stress, which is one of the crucial vibration responses to quantify how the vibration affects the system work behaviors, is thoroughly studied. Based on the semianalytical method, the sensitivity formula of forced torsional vibration of the working stress to the inertia and stiffness of the system are proposed.

(1) The sensitivity of working stress to inertia:

$$
\begin{aligned}
\frac{\partial \tau_{h}}{\partial J_{i}} & =\frac{1}{W_{h}}\left[\frac{\partial k_{h}}{\partial J_{i}}+\sum_{r}\left(\frac{\partial \varphi_{h+1}}{\partial J_{i}}+\frac{\partial \varphi_{h}}{\partial J_{i}}\right)\right] \\
& =\frac{1}{W_{h}} \sum_{r}\left(\frac{\partial \varphi_{h+1}}{\partial J_{i}}+\frac{\partial \varphi_{h}}{\partial J_{i}}\right) .
\end{aligned}
$$

(2) The sensitivity of working stress to stiffness:

$$
\begin{aligned}
\frac{\partial \tau_{h}}{\partial k_{i}} & =\frac{1}{W_{h}}\left[\frac{\partial k_{h}}{\partial k_{i}}+\sum_{r}\left(\frac{\partial \varphi_{h+1}}{\partial k_{i}}+\frac{\partial \varphi_{h}}{\partial k_{i}}\right)\right] \\
& =\frac{1}{W_{h}} \sum_{r}\left(\frac{\partial \varphi_{h+1}}{\partial k_{i}}+\frac{\partial \varphi_{h}}{\partial k_{i}}\right) .
\end{aligned}
$$

From formulas (12) and (13), it is known that the additional torsional vibration stress is closely related to the coupling stiffness.

\section{The Stiffness Identification of Flexible Coupling Based on Torsional Vibration Test}

6.1. Parameters Identification Method with Test Data. It is effective and feasible to identify the system natural parameters including damping and stiffness matrix by analyzing test data of vibration responses mathematically [25]. To avoid missing mode information and minimize the influence of noise, frequency analysis method is adopted in this test.

According to the approximation method of nonlinear vibration theory, the system frequency response function can be approximately expressed as follows:

$$
f\left(\boldsymbol{\omega}_{0}, \mathbf{C}, \ldots, \mathbf{A}, \boldsymbol{\sigma}\right)=0,
$$

where $\mathbf{A}$ is the matrix of torsional vibration amplitude and $\sigma$ is the matrix of coordination value.

A and $\sigma$ can be obtained by test. And a group of test data $\left(a_{i}, \sigma_{i}\right), i=1,2, \ldots, n$ are taken into the formula (14) to fit the curve of frequency response function. Moreover, the error is caused by the errors of test method and measure instruments.

$$
\delta_{i}=f\left(\omega_{0}, c, \ldots, a_{i}, \sigma_{i}\right) .
$$

The sum of each error square is

$$
\Delta=\sum_{i=1}^{n} \delta_{i}^{2}=\sum_{i=1}^{n}\left[f\left(\omega_{0}, c, \ldots, a_{i}, \sigma_{i}\right)\right]^{2} .
$$

To minimize the value of $\Delta$, the partial derivation of $\Delta$ to each variable is set to 0 . And the algebraic equations are obtained.

$$
\left\{\begin{array}{c}
\frac{\partial \Delta}{\partial \omega_{0}}=0 \\
\frac{\partial \Delta}{\partial c}=0 \\
\vdots \\
\frac{\partial \Delta}{\partial \delta}=0
\end{array}\right.
$$

The forced vibration equation of coupling is shown by 


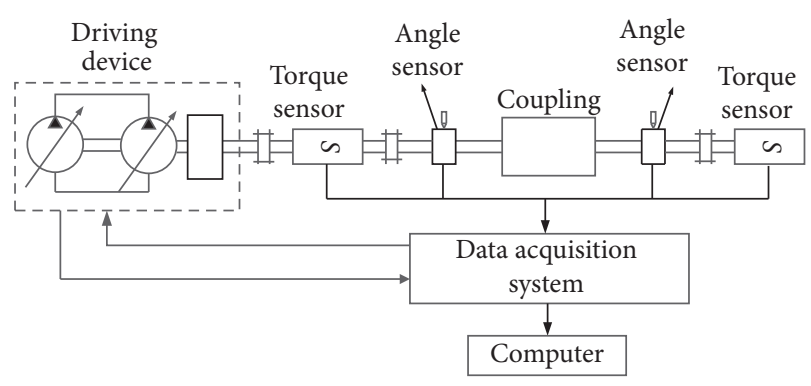

(a)

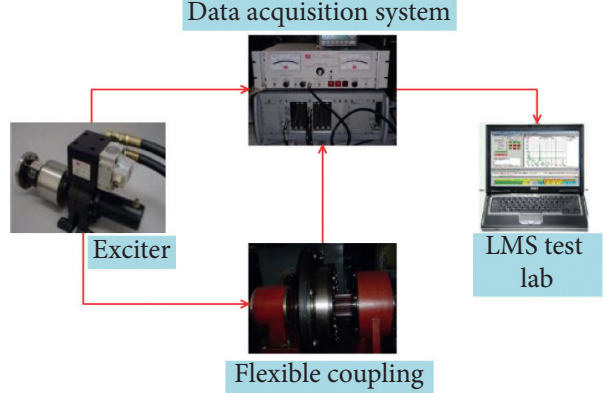

(b)

Figure 14: Test devices.

$$
\ddot{x}+2 \varepsilon \mu \dot{x}+\omega_{0}^{2} x+\varepsilon \alpha x^{3}=\sum_{j=1}^{2} \varepsilon k_{j} \cos \left(j \omega_{0} T_{0}+j \sigma T_{1}+\varphi_{j}\right) .
$$

The implicit function of coupling stable response is deduced as

$$
\mu^{2} a^{2}+\left(\sigma-\frac{3 \alpha}{8 \omega_{0}} a^{2}\right)^{2} a^{2}-\frac{k_{1}^{2}}{4 \omega_{0}^{2}}=0 .
$$

If $P_{1}=\mu^{2}, \quad P_{2}=\left(-3 \alpha / 4 \omega_{0}\right), \quad P_{3}=\left(9 \alpha^{2} / 64 \omega_{0}^{2}\right)$, and $P_{4}=\left(-k_{1}^{2} / 4 \omega_{0}^{2}\right)$, formula (19) is transferred to

$$
\left(\sigma^{2}+P_{1}\right) a^{2}+\sigma P_{2} a^{4}+P_{3} a^{6}+P_{4}=0 .
$$

After substituting a set of frequency response test data $\left(a_{i}, \sigma_{i}\right), i=1,2, \ldots, n$ into formula (21), the total variance of the vibration amplitude is obtained.

$$
\Delta=\sum_{i=1}^{n}\left[\left(\sigma_{i}^{2}+P_{1}\right) a_{i}^{2}+\sigma_{i} P_{2} a_{i}^{4}+P_{3} a_{i}^{6}+P_{4}\right]^{2} .
$$

According to formula (19), the partial derivations of $\Delta$ to $P_{1}, P_{2}, P_{3}$, and $P_{4}$ are all set to be 0 . And the equation about the relation between the test data and the identified parameters is deduced.

$$
\left[\begin{array}{cccc}
\sum_{i=1}^{n} a_{i}^{4} & \sum_{i=1}^{n} \sigma_{i} a_{i}^{6} & \sum_{i=1}^{n} a_{i}^{8} & \sum_{i=1}^{n} a_{i}^{2} \\
\sum_{i=1}^{n} \sigma_{i} a_{i}^{6} & \sum_{i=1}^{n} \sigma_{i}^{2} a_{i}^{8} & \sum_{i=1}^{n} \sigma_{i} a_{i}^{10} & \sum_{i=1}^{n} \sigma_{i} a_{i}^{4} \\
\sum_{i=1}^{n} a_{i}^{8} & \sum_{i=1}^{n} \sigma_{i} a_{i}^{10} & \sum_{i=1}^{n} a_{i}^{12} & \sum_{i=1}^{n} a_{i}^{6} \\
\sum_{i=1}^{n} a_{i}^{2} & \sum_{i=1}^{n} \sigma_{i} a_{i}^{4} & \sum_{i=1}^{n} a_{i}^{6} & n
\end{array}\right]\left[\begin{array}{c}
P_{1} \\
P_{2} \\
P_{3} \\
P_{4}
\end{array}\right]=\left[\begin{array}{c}
-\sum_{i=1}^{n} \sigma_{i}^{2} a_{i}^{4} \\
-\sum_{i=1}^{n} \sigma_{i}^{3} a_{i}^{6} \\
-\sum_{i=1}^{n} \sigma_{i}^{2} a_{i}^{8} \\
-\sum_{i=1}^{n} \sigma_{i}^{2} a_{i}^{2}
\end{array}\right] .
$$

Therefore, the system natural parameters $\omega_{0}$ and $c$ can be recognized by solving formula (22).

6.2. Torsional Vibration Test of Flexible Coupling. The test bench is designed for torsional vibration test of flexible coupling. Both system input parameters and vibration response parameters are tested. According to the fitting frequency response function, the system natural parameters are identified based on the test data processing.

A torsional vibration test system (XCITE 1300T-2 System), a data acquisition system (LMS-SC310), and a computer are adopted for the test (as shown in Figure 14).

The test bench is shown in Figure 15.

Both $\theta_{1}$ (input angular displacement), $T_{1}$ (input torque) and $\theta_{2}$ (output angular displacement), $T_{2}$ (output torque) are measured. Therefore, the accurate frequency response curve is obtained based on data processing.

The sine signal is used as the vibration driving source signal to perform a sweep sine test. The frequency range of the sine sweep test is 1 to $50 \mathrm{~Hz}$. The average input torque is $500 \mathrm{Nm}$. And the input fluctuate torque is $80 \mathrm{Nm}$. The fitting curve of the coupling frequency response test data based on the least square method is shown in Figure 16.

Based on the test data, iteration method is adopted for calculation. And the iteration result of damping satisfies the following equation:

$$
\left|\frac{c_{c 2}-c_{c 1}}{c_{c 1}}\right|<\delta_{e}
$$

where $\delta_{e}$ is the iteration error.

Therefore, a set of damping values is obtained. The curve of damping coefficient about frequency is fitted according to the least square method (as shown in Figure 17). The inflection point of the curve indicates that this point has the minimum iteration error $\delta_{e}$. And it indicates that its value is the recognized coupling damping coefficient. Therefore, the 


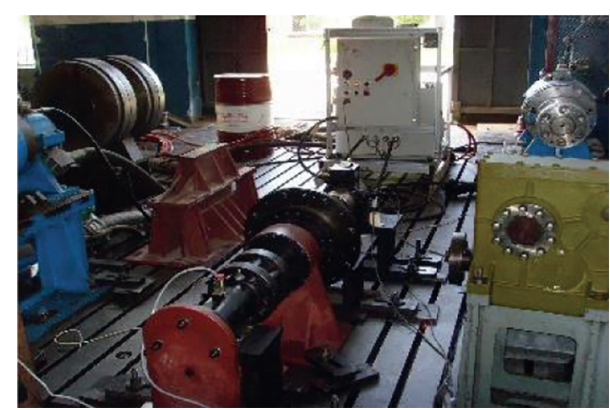

FIgURE 15: Test bench.

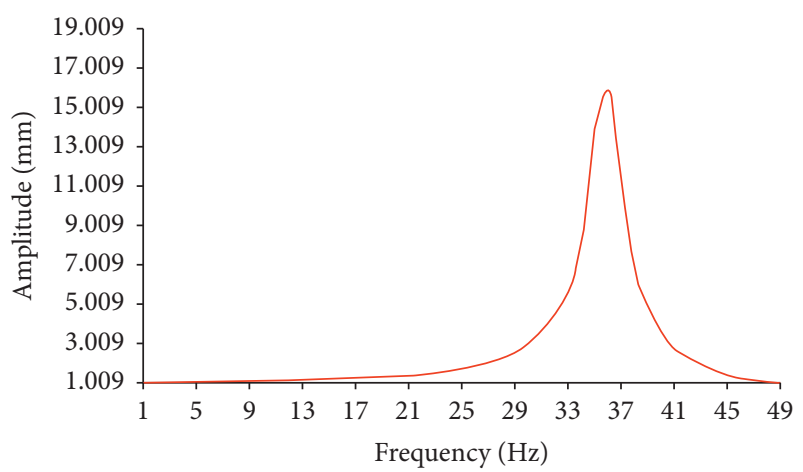

FIgURE 16: The fitting curve of frequency response.

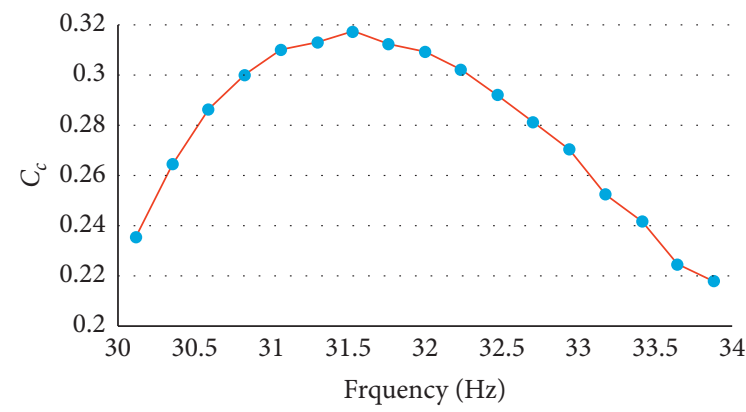

Figure 17: Recognized coupling damping coefficient.

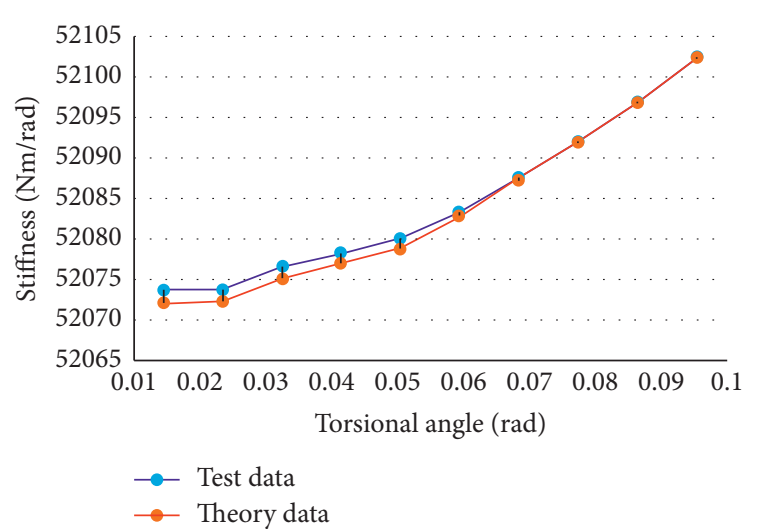

Figure 18: Recognized coupling stiffness and its theoretical result.

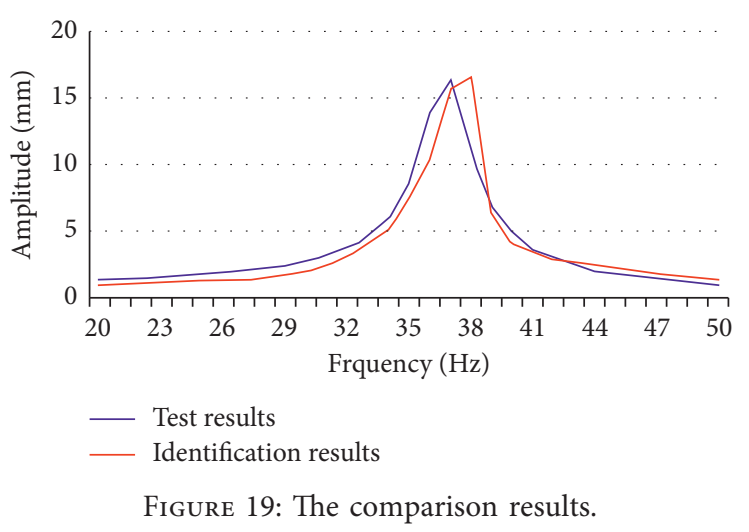

value of coupling damping coefficient is 0.317 as shown in Figure 17.

The coupling stiffness $\left(K_{c}\right)$ is relevant to the torsional angle of the coupling $(\theta)$. And it can be demonstrated by the following formula:

$$
K_{c}=\frac{1}{q_{1}}+\frac{1}{q_{2}^{3}} \theta^{2}-o\left(\theta^{4}\right),
$$

where $q_{1}$ and $q_{2}$ are the weighting coefficients determined by coupling design parameters.

When the coupling works with a certain torsional angle, the coupling stiffness is constant. According to the aforementioned recognized method, the coupling stiffness for each specific torsional angle is identified based on the test data, as shown in Figure 18. The theoretical calculation results are also shown in Figure 18.

Figure 18 shows that the stiffness identified by the test is consistent with the theoretical results. Small error caused by certain assumptions can be neglected.

The identified parameters (damping and stiffness) are substituted in equation (19). And the comparison results of test and simulation with identified parameters are shown in Figure 19.

Figure 19 shows that the amplitude frequency characteristic curves obtained by simulation using identification parameters are close to the test results. It is proved that the parameter identification method is feasible and accurate.

\section{Conclusions}

Aiming at a vehicle power train, torsional natural vibration model of the vehicle power train is constructed based on the concentrated mass method. The influences of coupling stiffness on vehicle power train dynamics behaviors are thoroughly analyzed. The sensitivity formulas of free and forced torsional vibrations are derived. Moreover, according to the sensitivity analysis results, a coupling stiffness identification method based on bench test data is proposed.

(1) The torsional dynamics model of certain vehicle power train is constructed based on the dynamics 
models of system crucial components. And the influence of coupling stiffness on vehicle power train dynamics characteristics is analyzed. The distribution laws of the first four-order natural frequencies from the 4 th to the 6 th gear shift, additional torsional stress and vibration amplitude are obtained. It shows the coupling with the smaller stiffness has the obvious damping effect.

(2) With the condition of the 4th and 5th gear, the most sensitive parameters of the $3 \mathrm{rd}$ - and the 4 th-order free vibration are obtained, according to the sensitivity analysis of the torsional natural frequency and mode shape to the system inertia and stiffness. The most sensitive parameters of torsional natural frequency are $J_{22}, J_{23}, K_{7}, K_{18}$, and $K_{19}$, including gear inertia, coupling stiffness, and transmission shaft stiffness. The most sensitive parameters of torsional vibration mode are $J_{4}, J_{6}, J_{7}, K_{16}, K_{22}$, and $K_{27}$, including engine equivalent inertia, gear inertia, and transmission shaft stiffness. In addition, according to the sensitivity analysis of torsional forced vibration response, it shows that the additional torsional vibration stress is closely related to the coupling stiffness.

(3) A coupling parameter identification method based on the approximate frequency response curve of the system is proposed. The torsional vibration test bench is designed based on the working principle of Geislinger coupling. And the test frequency response results are obtained. Moreover, the coupling damping and stiffness are identified according to the proposed parameters identification method. The approved stiffness of the test is consistent with the theory result. It indicates that this method is feasible and accurate.

$\begin{array}{ll}\text { Abbreviations } \\ k_{c}: & \text { Geislinger coupling stiffness } \\ c_{c}: & \text { Geislinger coupling damping } \\ \omega_{c 0}: & \text { Natural frequency of coupling } \\ k_{\mathrm{cs}}: & \text { Static stiffness of coupling } \\ \kappa: & \text { Geislinger coupling damping factor } \\ T_{0}: & \text { Stable working torque of coupling } \\ T_{\mathrm{KN}}: & \text { Rated coupling torque } \\ k_{g}: & \text { Gear meshing stiffness } \\ c_{g}: & \text { Gear meshing damping } \\ e_{g}: & \text { Gear comprehensive error } \\ R_{g 1}, R_{g 2}: & \text { Radius of driving and driven gear } \\ J_{g 1}, J_{\mathrm{g} 2}: & \text { Inertias of driving and driven gear } \\ \xi_{g}: & \text { Gear meshing damping ratio } \\ e_{0}, e_{r}: & \text { Constant and amplitude of gear teeth error } \\ f_{f 1}, & \text { Profile tolerance of driving and driven gear } \\ f_{f 2}: & \\ f_{\mathrm{pb} 1}, & \text { Festival deviation of driving and driven gear } \\ f_{\mathrm{pb} 2}: & \\ T_{g}: & \text { Gear meshing period } \\ \phi_{g}: & \text { Gear meshing phase angle }\end{array}$

$k_{s}$ : Torsional stiffness of transmission shaft

$c_{c}$ : Torsional damping of transmission shaft

$G_{s}: \quad$ Shaft shear modulus

$I_{\mathrm{ps}}: \quad$ Polar moment of inertia of the cross section

$\omega_{s}: \quad$ Shaft natural frequency

$M_{\mathrm{Pb}}$ : Torque of pump wheel

$M_{\mathrm{Tb}}$ : Torque of turbine wheel

$n_{\mathrm{Pb}}$ : Torsional speed of pump wheel

$n_{\mathrm{Ib}}$ : Torsional speed of turbine wheel

$J_{\mathrm{Pb}}$ : $\quad$ Equivalent inertia of pump wheel

$J_{\mathrm{Tb}}$ : $\quad$ Equivalent inertia of turbine wheel

$k_{b}$ : Torsional stiffness of power transmission between pump wheel and turbine wheel

$c_{b}$ : Viscous damping coefficient of hydraulic torque convertor

$A_{r}: \quad$ The $r$ order sine component of torsional vibration amplitude

$B_{r}: \quad$ The $r$ order cosine component of torsional vibration amplitude

$\omega_{r}: \quad$ The $r$ order angular frequency of external excitation

$i_{b}$ : Transmission ratio of hydraulic torque convertor

J: $\quad$ System inertia matrix

C: $\quad$ System damping matrix

K: $\quad$ System inertia stiffness matrix

$\varphi(t)$ : Column vectors of torsional angle displacement

$\dot{\varphi}(t)$ : Column vectors of torsional angle speed

$\ddot{\varphi}(t)$ : Column vectors of torsional angle acceleration

$\omega_{i}$ : $\quad$ System natural frequency

$\varphi_{i}: \quad$ System mode vector

A: $\quad$ Matrix of torsional vibration amplitude

$\sigma: \quad$ Matrix of coordination value

$\delta_{i}: \quad$ Error of test method and measure instruments

$\theta_{1}$ : $\quad$ Test input angular displacement

$T_{1}$ : $\quad$ Test input torque

$\theta_{2}$ : Test output angular displacement

$T_{2}$ : $\quad$ Test output torque

$\delta_{e}: \quad$ Iteration error

$q_{1}, q_{2}$ : Weighting coefficients.

\section{Data Availability}

The data used to support the findings of this study are available from the corresponding author upon request.

\section{Conflicts of Interest}

The authors declare that they have no conflicts of interest regarding the publication of this paper.

\section{Acknowledgments}

This work was partially supported by the National Natural Science Foundation of China (Grant no. 51975500) and the Natural Science Foundation of Fujian Province, China (Grant no. 2019J01862). The authors would like to express their gratitude to the financial support. 


\section{References}

[1] C. L. Xiang, W. He, H. Liu, and Y. Ma, "Transient dynamics analysis of tracked vehicle transmission during gear shift process," Transactions of the Chinese Society for Agricultural Machinery, vol. 47, no. 4, pp. 288-293, 2016.

[2] O. Çakar, "A method for shifting natural frequencies of a dynamic system to desired values with concentrated mass modifications," Journal of Vibroengineering, vol. 20, no. 1, pp. 1-12, 2018.

[3] A. Matsuo, S. Ishikawa, S. Kijimoto, and Y. Akayama, "Coupled analysis of two-dimensional acoustic and membrane vibration by concentrated mass model," Advances in Mechanical Engineering, vol. 2014, no. 5, pp. 347-354, 2017.

[4] J. Wei, A. Zhang, D. Qin et al., "A coupling dynamics analysis method for a multistage planetary gear system," Mechanism and Machine Theory, vol. 110, pp. 27-49, 2017.

[5] J. Wei, A. Zhang, D. Qin et al., "Coupling vibration analysis for planetary gear system considering flexible structure," Journal of Mechanical Engineering, vol. 53, no. 1, pp. 1-12, 2017.

[6] B. H. Liu, T. T. Song, L. H. Lin et al., "Sensitivity analysis and optimization of torsional vibration characteristics of pure electric vehicle transmission system," Drive System Technique, vol. 2, no. 8, pp. 3-7, 2017.

[7] L. Q. Song, H. E. Niu, L. P. Zeng et al., "A study on the modeling and torsional vibration attenuation for vehicle powertrain system based on unit analysis," Automotive Engineering, vol. 8, no. 9, pp. 866-874, 2015.

[8] Y. Guo and R. G. Parker, "Sensitivity of general compound planetary gear natural frequencies and vibration modes to model parameters," Journal of Vibration \& Acoustics, vol. 132, no. 1, pp. 655-672, 2010.

[9] W. Sun, X. Ding, J. Wei, X. Hu, and Q. Wang, "An analyzing method of coupled modes in multi-stage planetary gear system," International Journal of Precision Engineering and Manufacturing, vol. 15, no. 11, pp. 2357-2366, 2014.

[10] Q. Zhang, J. H. Deng, and H. Y. Wang, "Study on the effect of torsional stiffness of driveline's component on torsional vibration modes of RWD driveling," Noise and Vibration Control, vol. 10, no. 5, pp. 49-52, 2011.

[11] D. S. Zhang and H. Wang, "Optimization of vehicle drivetrain torsional vibration characteristics based on sensitivity analysis," China Mechanical Engineering, vol. 24, no. 5, pp. 685689, 2013.

[12] G. Q. Shu, B. Wang, and X. Y. Liang, "Torsional vibration reduction analysis of variable damping torsional vibration for engine crankshaft," Journal of Tianjin University (Science and Technology), vol. 48, no. 1, pp. 19-24, 2015.

[13] J. Y. Liang, J. L. Zhang, X. R. Ma et al., "Control strategy optimization for hybrid electric vehicle based on multi-chaotic operators genetic algorithm," Journal of Shanghai Jiao Tong University, vol. 49, no. 4, pp. 442-429, 2015.

[14] V. Berbyuk, "Design optimization of torsional vibration absorbers for heavy-duty truck drivetrain systems," Vibration, vol. 2, no. 3, pp. 240-264, 2019.

[15] L. Zeng, C. Qiping, and S. Liquan, "Nonlinear vibration of a dual mass flywheel considering the friction torque and clearance variation characteristics of the stiffness of damping spring," Journal of Vibration and Shock, vol. 37, no. 6, pp. 231-237, 2018.

[16] P. D. Walker and N. Zhang, "Numerical investigations into shift transients of a dual clutch transmission equipped powertrains with multiple nonlinearities," Journal of Vibration and Control, vol. 21, no. 8, pp. 1473-1486, 2015.

[17] Z. Chen, M. Yang, H. Pu et al., "Analysis of parameter matching characteristics for dual mass flywheel of front-engine rear-drive transmission," Mechanical Engineering \& Automation, vol. 210, pp. 85-87, 2018.

[18] W. Li, Research and Optimization of Torsional Vibration Model of Automotive Powertrain, Jiangsu University, Nanjing, China, 2019.

[19] J. Margielewicz, T. Opasiak, D. Gąska, and G. Litak, "Study of flexible couplings non-linear dynamics using bond graphs," Forschung im Ingenieurwesen, vol. 83, no. 2, pp. 317-323, 2019.

[20] G. Sheng, Y. Li, C. Ding et al., "Dynamic torsion stiffness analysis of gear-type rubber coupling," Journal of Mechanical Transmission, vol. 37, no. 9, pp. 129-132, 2013.

[21] Y. Qiu, Y. Duan, and X. Gu, "Design and static characteristic analysis of a new rubber coupling," Journal of Mechanical Transmission, vol. 44, no. 8, pp. 103-107, 2020.

[22] Y. Xia, J. Pang, L. Yang, Q. Zhao, and X. Yang, "Study on vibration response and orbits of misaligned rigid rotors connected by hexangular flexible coupling," Applied Acoustics, vol. 155, pp. 286-296, 2019.

[23] K.-H. Lee, J.-E. Park, and Y.-K. Kim, "Design of a stiffness variable flexible coupling using magnetorheological elastomer for torsional vibration reduction," Journal of Intelligent Material Systems and Structures, vol. 30, no. 15, pp. 22122221, 2019.

[24] H. Liu, Torsional Vibration Dynamic Simulation and Analysis of Vehicle Powertrain, Beijing Institute of Technology, Beijing, China, 2003.

[25] H. M. Zhou and R. Wang, Test Signal Processing Technology, Beijing University of Aeronautics and Astronautics Press, Beijing, China, 2004. 